\title{
A Schematic for Focusing on Youth in Investigations of Community Design and Physical Activity
}

\author{
Kevin J. Krizek, PhD; Amanda S. Birnbaum, MPH, PhD; David M. Levinson, PhD
}

\section{Synopsis}

This paper provides a first step in addressing special considerations for youth in a relatively new area of physical activity research. After reviewing the urgent need for novel approaches to increasing physical activity, the growing interest in the effects of community design are discussed. Although most discussion on this topic has focused on adults, there are important differences between youth and adults that warrant a special focus on youth and need to be accounted for. This article presents a schematic that accounts for how and where youth spend their time, decomposing the day into time spent in travel and time spent at destinations, and identifying portions of those times that are spent engaged in physical activity. By focusing on both spatial and behavioral dimensions of youth time, the schematic may help organize and advance scientific inquiry into the relationships between community design and physical activity specifically for youth. (Am J Health Promot 2004;0[0]:000-000.)

\section{INTRODUCTION}

Physical inactivity is a major public health concern for the U.S. population, particularly youth. National data indicate that nearly one third of youth are insufficiently ac-

Kevin J. Krizek, PhD, is with the Urban and Regional Planning Program, University of Minnesota, Minneapolis, Minnesota. Amanda S. Birnbaum, MPH, PhD, is with the Department of Public Health, Weill Cornell Medical Center, New York, New York. David M. Levinson, PhD, is with the Department of Civil Engineering, University of Minnesota, Minneapolis, Minnesota.

Send reprint requests to Kevin J. Krizek, PhD, Urban and Regional Planning Program, University of Minnesota, 301 19th Ave S, Minneapolis, MN 55455 .

This manuscript was submitted October 16, 2002; revision were requested January 13, 2003, and July 7, 2003; the manuscript was accepted for publication August 27, 2003.

Am J Health Promot 2004;0(0):000-000.

Copyright (C) 2004 by American Journal of Health Promotion, Inc. $0890-1171 / 04 / \$ 5.00+0$ tive, and more than half of all youth fall far short of recommended levels of vigorous activity. ${ }^{1,2}$ These patterns persist despite widespread documentation and reporting of the health benefits of physical activity and the health risks associated with physical inactivity, overweight, and obesity. ${ }^{2,3}$ In addition to higher-than-ever proportions of overweight and obese children, ${ }^{4}$ there has also been an alarming rise among youth of type 2 diabetes, an obesityrelated disease historically seen almost exclusively with adult onset. ${ }^{5,6}$ In light of these trends, demand is increasing for new and expanded theories to explain these behavioral patterns and serve as the basis for novel intervention approaches.

One intriguing approach draws from the fields of public health and urban planning to suggest that levels of physical activity are related to patterns of urban development. These hypotheses are still relatively general in nature and are only recently being tested. Within this nascent area, little attention has been devoted to examining such relationships specifically for youth or providing a systematic approach for doing so. Because youth and adolescence represent unique parts of the life course that are particularly important in the development of lifelong behavior patterns, ${ }^{7,8}$ this is an important gap to fill. To that end, this paper provides a first step to adding a special youth focus to the scientific inquiry into the effects of community design on patterns of physical activity (defining youth as children ages 7 to 16 years, younger than driving age). After setting the context and making the case for a special focus on youth, we present a schematic designed to help frame further discourse and research, discuss its theoretical underpinnings, and briefly suggest its potential applications in future investigations.

\section{BACKGROUND AND CONTEXT}

Theoretical approaches that have been applied to physical activity research to date have mostly focused on single levels of analysis, for example, the individual, institutional, or community level rather than a multilevel approach that explicitly acknowledges multiple levels of behavioral influence, including possible cross-level interactions (e.g., be- 
tween individual and community characteristics). ${ }^{8}$ The greatest focus has been on individual-level constructs and processes. ${ }^{9,10}$ Empirical applications of these theories have generally explained relatively small proportions of variance in physical activity, ${ }^{9,11}$ prompting arguments that the stage is set for innovation to expand theoretical models to integrate individual characteristics with the broader social and physical environments in which human behavior occurs.

Interest from both the scientific and popular literature is increasingly focusing on possible causal links between community design and levels of physical activity. ${ }^{12-18}$ Specifically, the potential for a neighborhood designed to curb Americans' appetite for auto travel is a topic that has generated considerable interest. Sprawl-urban development characterized by low-density, detached single-family housing and dispersed commercial centers almost exclusively served by the automobile ${ }^{19,20}$ —has emerged as a possible culprit contributing to decreased levels of physical activity. Calls echoing throughout the transportation community urge compact development, a mixing of land uses, and urban design improvements (e.g., sidewalks, gridded streets, and street crossings). Planning proposals that incorporate such features have been dubbed "new urbanism" 21 and "smart growth." 22 In response to these calls, there has been a blizzard of research ${ }^{23-25}$ examining assertions that community redesign will help reduce the prevalence of automobile trips and increase walking, transit, and cycling trips. An outgrowth of this research yields a direct application for public health-the hypothesis that implementing smart growth principles will help foster and promote "active living," defined as a lifestyle in which people get at least 30 minutes of moderate physical activity as part of their daily routines. ${ }^{26}$

\section{THE NEED FOR A FOCUS ON YOUTH}

The above discussions, however, have focused almost entirely on adults. Notwithstanding an occasional reference to the special case of youth and other nondriving populations, ${ }^{13}$ few theories and hypotheses have been advanced that connect the built environment and physical activity specifically among youth. ${ }^{27}$ This is troubling in light of critical differences in needs and activities between youth and adults. Unlike most adults, youth are (1) required to spend a large part of the day at school ${ }^{28}$; (2) expected to use a considerable amount of their unobligated (nonschool) time for enrichment, recreation, and developmental activities ${ }^{29}$; (3) more likely to get physical activity through spontaneous play ${ }^{30}$; (4) unable to own or operate motor vehicles ${ }^{31}$; and (5) subject to restrictive laws and family rules governing their travel and destinations. ${ }^{32}$ These characteristics uniquely affect the major travel mode choices, destinations, and physical activities of youth. Consequently, relying solely on investigations of community design and adult physical activity is likely to miss important differences for youth.

In response, our work seeks to fill this gap by linking what is already known about youth physical activity with the current lines of inquiry concerning community design and physical activity. Results from an active line of research about youth physical activity are becoming widely available. ${ }^{33,34}$ Considerable progress has been made toward conceptualizing and empirically identifying determinants of youth physical activity, ${ }^{35-37}$ including demographic factors, ${ }^{38}$ psychological factors,${ }^{39}$ social and cultural factors, ${ }^{40-42}$ and environmental factors. ${ }^{36,43}$

Although elements of community design are certainly environmental, the research to date on environmental determinants of youth physical activity has focused more on access to physical activity equipment and facilities ${ }^{40}$ and programs ${ }^{28,35}$ and less on specific community design elements, such as street networks, transportation systems, and neighborhood walkability or bikability. In light of the current interest in the effects of such design elements on physical activity and initial progress in specifying particular elements that may affect adults' walking and cycling for transport and recreation, ${ }^{44}$ it is important to begin to fill this void in the literature on youth physical activity.

This task is undoubtedly difficult because community design determinants will differ by age (and probably other individual characteristics) of youth. For example, community design elements such as bicycle paths or a wellmarked pedestrian crosswalk system are more likely to encourage or facilitate physical activity in a 15-year-old than a 7-year-old, who instead values proximity to safe, fun playgrounds. Yet despite the difficulty, the compelling evidence of insufficient youth physical activity combined with evidence that physical activity and other obesity-related health behaviors track from adolescence into young adulthood $^{45}$ make this a worthy task. As discussed earlier, the preadolescent and adolescent years are a critical time for intervention to promote healthful lifelong behaviors. ${ }^{7,8,45}$

\section{A SCHEMATIC FOR FOCUSING ON YOUTH}

To help advance our understanding of how community design features may affect youth physical activity, we offer a schematic designed to help organize and guide further scientific inquiry in this area. The schematic is guided by existing literature on youth physical activity and the emerging literature on community design and physical activity. We draw from several related disciplines and take an approach that considers what King et al. ${ }^{9}$ term "choiceenabling" microenvironmental, mesoenvironmental, and macroenvironmental factors that affect physical activity and travel behavior, in addition to the more traditional "choice-driven" intrapersonal factors. We also draw from social ecological models of human behavior ${ }^{46-48}$ and utility theory. ${ }^{37}$ Social ecological models posit that in addition to intraindividual factors, human behavior is shaped by higher-level factors, including organizational, policy, social, and physical environments, as well as dynamic interactions across multiple domains. Utility theory posits that individuals behave in ways to maximize their own utility, which is unobservable. Utility theory has been central to advances in modeling behaviors involving discrete choices such as travel mode (e.g., walking, taking transit, or driving) and is useful for thinking about complex behaviors with multilevel determinants (i.e., psychosocial, economic, or behav- 


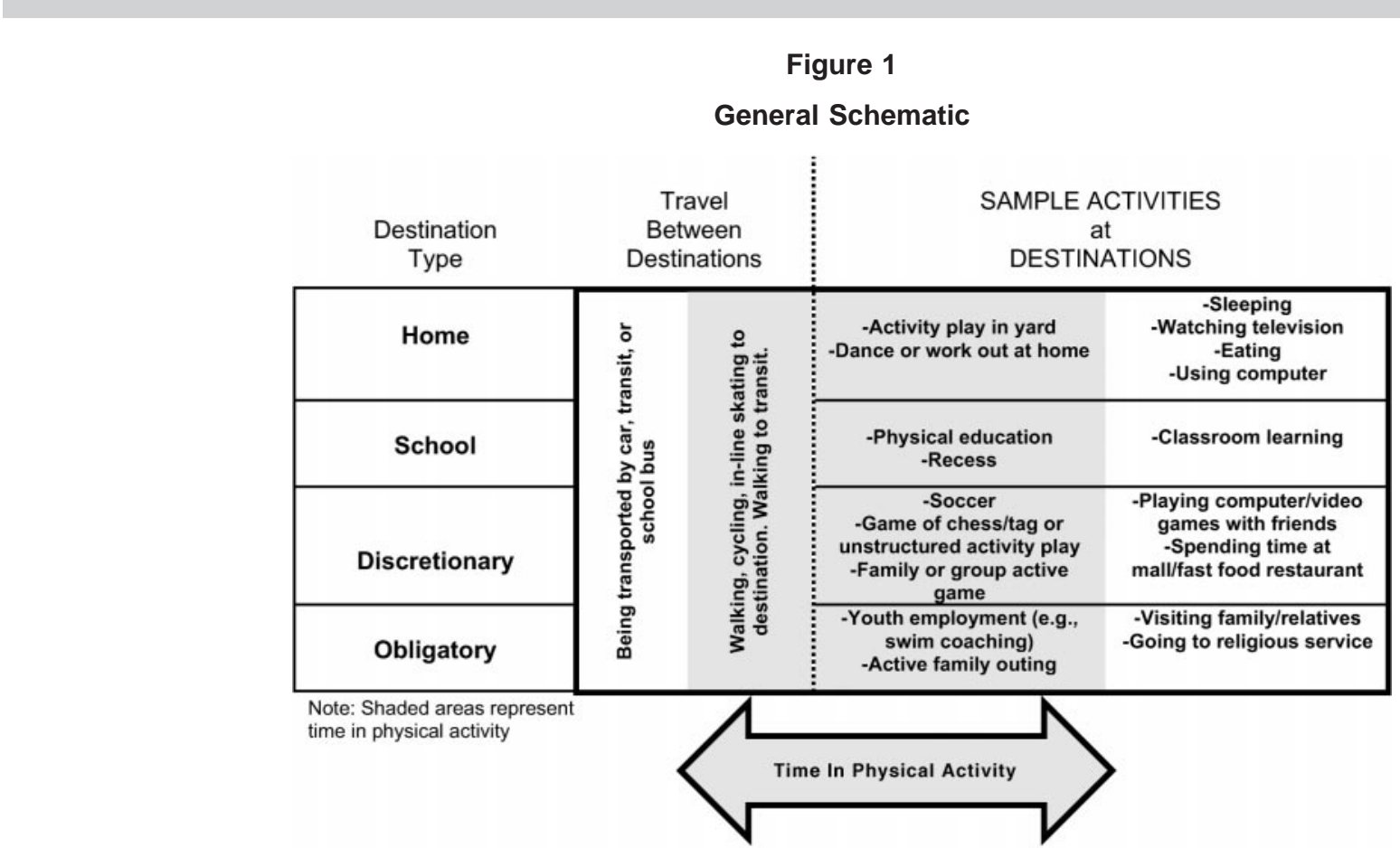

Illustration of youth daily time allocation to active and inactive travel and destinations.

ioral). By examining observed behaviors, we can infer bundles of activities that are preferred and estimate the willingness to engage in particular behaviors as a function of attributes associated with individuals, their families, and their physical and social environments.

Our approach is to focus on how youth spend their time. Both the empirical and theoretical sources suggest that youth allocation of time is a function of many factors that interact in complex ways. Unfortunately, there are few data available to provide full descriptions of how and where youth spend their time. Although travel data may be used for this purpose, the available data on youth travel behavior is limited because it is too general (and even a bit dated), ${ }^{49}$ examines only a specific purpose or program, ${ }^{50}$ is supply driven by looking only at the availability of destination opportunities, ${ }^{51}$ or is based on only afterschool activities. ${ }^{31}$ Few, if any, studies of how youth spend their time have incorporated geographic and/or spatial community features. ${ }^{31}$ Yet to help identify intervention opportunities, it is important to understand where youth go, how they get there, how long they spend, what they do there, and what influences their allocation of time and activities.

Using a logic approach, one way to account completely for time is to decompose it into time spent in travel and time spent at destinations. Because of some general similarity in how most youth spend their time (attending school daily, sleeping and doing some activities at home daily, spending some free time with friends or peers, or engaged in activities outside the home most days), we assume that some common patterns in travel needs and types of destinations exist that apply to most youth. With- in each of those categories, some (or all) of the time is spent in sedentary or inactive behaviors, and other time may be spent engaging in physical activity.

Figure 1 presents these assumptions visually. The total daily time budget of youth $(24 \mathrm{~h} / \mathrm{d}$ for $60 \mathrm{~min} / \mathrm{h}=1440$ $\mathrm{min} / \mathrm{d}$ ) is represented by the rectangle outlined in heavy solid lines. The dotted line represents a distinction between time spent at destinations (area to the right of the dotted line) and time spent traveling between destinations (area to the left). The latter area could be considered analogous to the concept of a travel time budget ${ }^{52}$ that has empirically studied ${ }^{53}$ and reviewed ${ }^{54}$ but never for a youth population. Note that travel may occur between any two types of destinations even if not represented as contiguous. The shaded area, discussed further below, represents time spent engaged in physical activity.

We distinguish among four types of destinations where youth travel to and spend their time: home, school, obligatory (e.g., extracurricular and family commitments, afterschool lessons, other commitments), and discretionary (e.g., unstructured time and activities, visiting a friends' home, and/or other locations for free play and recreation). This approach has been used previously to classify adult travel into similar groupings (subsistence, maintenance, and discretionary) ${ }^{55}$ and is modified here to more appropriately describe the lifestyles and activities of youth.

By distinguishing among four destination types, we hope to provide a relatively parsimonious classification scheme but one that is detailed enough to allow some useful generalizations regarding the types of destinations where youth spend most of their time and the types of destinations where design features to encourage physical 
activity might be most effective or have the greatest impact (for example, by increasing access to school or home through walking, biking, or skating, by increasing youth access to recreational facilities, or by modifying existing destinations to increase on-site physical activity).

As noted above, of central importance is the distinction between physically active vs. inactive time (Figure 1). In travel, physically active time includes nonmotorized travel (e.g., walking, cycling, in-line skating); physically inactive travel is characterized by the youth as a passenger being transported without notable energy expenditure. Similarly, time spent at destinations is either active or inactive. Figure 1 provides examples of both active and inactive behaviors at each type of destination. For example, physically inactive time at home may include sleeping or using the computer; active discretionary time could be playing an unstructured game of tag in a park. From a public health perspective, the gray, shaded areas representing time spent in physical activity are critical and should be targeted for expansion. Figure 1 makes explicit that both travel time and time spent at destinations can contribute to accrual of physical activity throughout the day.

The actual amount of time allocated across destination types and in travel between them is not likely to be equally distributed as suggested by the simple rectangular figure. To describe particular youth populations more accurately, graphic changes may be made. For example, the schematic can reflect different patterns of time allocation across destination types (by adjusting row heights to affect area), different physical activity patterns (by adjusting the area and placement of the gray shading), or varying portions of time spent at a destination or in travel (by adjusting the dotted line). Such adaptations would produce variations of the general schematic that could be used to help guide needs assessments, identify gaps in our knowledge of youth activities, and describe subpopulations of youth, such as more active and more sedentary youth. In conjunction with information on the social, physical, and institutional environments of particular populations, these graphic variations could also be used to identify time segments and their corresponding physical locations that are more or less malleable or amenable to intervention.

Figure $2(a, b$, and $c)$ is an example of variations on the general schematic adapted to three different, relatively common patterns of youth behavior. The total time within the bold black lines is the same-1440 minutes. In each variation, the bulk of time is spent at home and school; this is intuitively consistent with where children spend most of their 1440 minutes. However, differences in how active or inactive their school and home time and travel are, as well as differences in how nonschool time is spent, can yield dramatically different patterns and quantities of shaded (active) time. Figure 2a represents the time allocation of a child who bicycles to and from school and frequently participates in competitive sports practices and tournaments, spending few waking hours at home. Figure $2 \mathrm{~b}$ represents the time allocation of a child who is transported to and from school and engages in a lot of sedentary behavior but participates actively in physical education class and uses active travel to visit friends. Figure 2c, which is almost totally without shading, represents the time allocation of a child who is transported most places and engages almost exclusively in sedentary behaviors, is not active at school, and does very little physical activity most days.

\section{RESEARCH APPLICATIONS}

As described above, there has been little work that considers how the relationships between community design and physical activity may be unique for youth. To begin to answer this question, we need more information about where and how youth spend their time. In the early stages of this work, the general schematic presented here may be useful as a guide to help ensure that instruments and measures are designed to provide the necessary information to empirically refine the representation of time allocation and to specifically incorporate details on both spatial (destinations) and behavioral (active or inactive) dimensions. This information will then help refine the schematic to describe the youth population. One general adaptation may be useful, or it may instead prove most useful to develop separate variations for boys and girls, urban and rural youth, active and sedentary youth, and so on. These variations could be augmented with maps, tables, or qualitative data to create a rich description of where and how youth time is allocated.

An intermediate and requisite step would include more detailed youth activity monitoring and recording to allow the precise identification of times and locations of activity. For this type of advanced investigation, existing methods such as physical activity and travel diaries or recalls, as well as electronic monitors, may be able to be adapted and refined, for example, by adding multiple prompts to record activity or increasing participant incentives. New methods, such as video surveillance, global positioning systems, and other technological advances, are also likely to be instrumental. These techniques would invariably be married with geographic information systems to develop and operationally define a set of quantitative urban form measures. ${ }^{26}$

With more complete data on youth time allocation, including spatial and behavioral details, the schematic may also be a useful tool to help with hypothesis generation. To date, hypotheses concerning community design and physical activity have been fairly general. Pikora and colleagues ${ }^{44}$ recently presented a conceptual framework that identified four "features" of the physical environmentfunctional, safety, aesthetic, and destination-expected to affect walking and cycling behavior. Within each category, they offered several key elements (such as traffic, streetscape, and views) and concrete candidate "items" that operationally define the elements. These represent specific hypotheses that have the potential to move scientific inquiries forward considerably. Similar work is needed to ensure that youth are not left behind, and the schematic presented here may be one useful tool for such work.

As the science progresses, variations of the schematic tailored to represent particular target populations may be helpful for identifying intervention opportunities. In fact, 
Figure 2

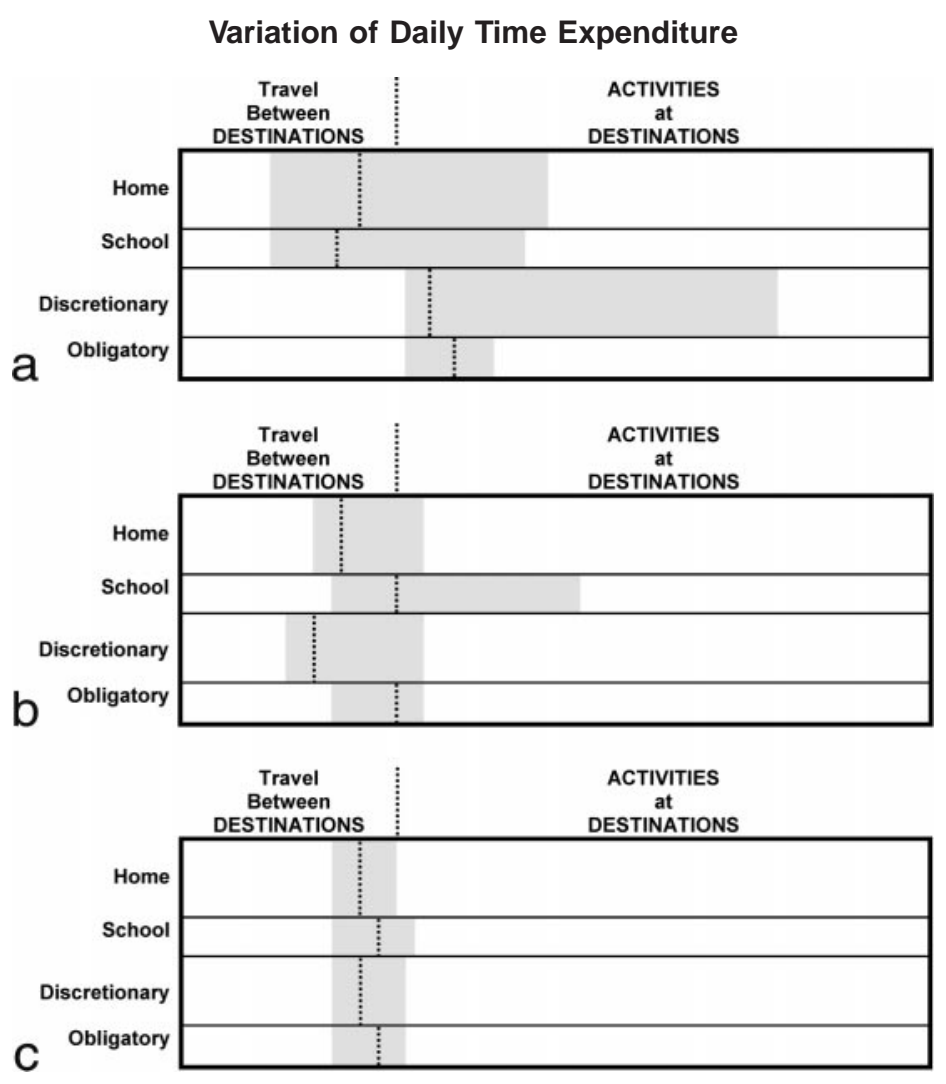

a) Variation of daily time expenditure for youth who bicycle to and from school and frequently participate in (and is transported to) non-school-based, far-away competitive sports practices and spend relatively little time at home.

b) Variation of daily time expenditure for youth who are driven to school, actively participate in physical education class (but no other school-based activities), frequently in-line skate to visit friends in a different neighborhood, and watch considerable television but engage in few obligatory activities.

c) Variation of daily time expenditure for youth who primarily engage in sedentary behavior, are transported most places, and rarely engage in any form of physical activity.

collecting and filling in information to help tailor local variations on the schematic could be one potential way to engage community members and stakeholders interested in promoting youth activity. From the "lifestyle activity" approach that acknowledges the benefits of accruing minutes of physical activity throughout the day, ${ }^{2,30,56,57}$ such information would enrich interventionists' understanding of opportunities and barriers in both space and time for youth to do so.

\section{CONCLUSION}

In this paper, we argue that because of key differences between youth and adult populations, a special focus on youth is warranted as the science of community design and physical activity advances. To facilitate this focus, we offer a schematic as a tool for organizing data about how and where youth spend their time and identifying possible areas for intervention to increase the proportion of time that is spent being physically active. The schematic is grounded in social, ecological models of human behavior and utility theory and is amenable to use with complementary theories as well. As the field of inquiry concerning community design and physical activity advances, it is important to consider how the relationships may be different for youth. The schematic offered here has not yet been empirically tested; in conjunction with a strong theoretical guide that considers individual- and community-level (and higher-level) influences on behavior, it provides a useful tool for doing so in future work.

\section{References}

1. Grunbaum JA, Kann L, Kinchen SA, et al. Youth risk behavior surveillance-United States, 2001. MMWR Surveill Summ. 2002;51(4):1-62.

2. US Department of Health and Human Services. Physical Activity and Health: A Report of the Surgeon General. Atlanta, Ga: Dept of Health and Human Services, Centers for Disease Control and Prevention, National Center for Chronic Disease Prevention and Health Promotion; 1996.

3. McGinnis JM, Foege WH. Actual causes of death in the United States. JAMA. 1993;270:2207-2212.

4. US Department of Health and Human Services. The Surgeon General's Call to Action to Prevent and Decrease Overweight and Obesity. Rockville, Md: US Dept of Health and Human Services, Public Health Service, Office of the Surgeon General; 2001. 
5. Brosnan CA, Upchurch S, Schreiner B. Type 2 diabetes in children and adolescents: an emerging disease. J Pediatr Health Care. 2001;15:187-193.

6. Rosenbloom AL, Joe JR. Emerging epidemic of type 2 diabetes in youth. Diabetes Care. 1999;22:345-354.

7. Dryfoos JG. Safe Passage: Making It Through Adolescence in a Risky Society. New York, NY: Oxford University Press; 1998.

8. Perry CL. Preadolescent and adolescent influences on health. In: Smedley BD, Syme SL, eds. Promoting Health: Intervention Strategies from Social and Behavioral Research Division of Health Promotion and Disease Prevention. Washington, DC: National Academy Press; 2000:217-253.

9. King AC, Stokols D, Talen E, Brassington GS, Killingsworth R. Theoretical approaches to the promotion of physical activity: forging a transdisciplinary paradigm. Am J Prev Med. 2002;23(2 suppl):15-25.

10. Sallis JF, Bauman A, Pratt M. Environmental and policy interventions to promote physical activity. Am J Prev Med. 1998;15:379-397.

11. Baranowski T, Anderson C, Carmack C. Mediating variable framework in physical activity interventions: how are we doing? How might we do better? Am J Prev Med. 1998;15:266-297.

12. Frank LD. Land use and transportation interaction: implications on public health and quality of life. J Planning Educ Res. 2000;20:6-22.

13. Frank LD, Engelke P. How Land Use Transportation Systems Impact Public Health: A Literature Review of the Relationship Between Physical Activity and Built Form. Atlanta, Ga: Centers for Disease Control and Prevention, Division of Nutrition and Physical Activity, Physical Activity and Health Branch; 2002

14. Jackson RJ, Kochtitzky C. Creating a healthy environment: the impact of the built environment on public health. Available at: www.sprawlwatch.org/health.pdf. Accessed April 15, 2003.

15. Kurth J. As the metro Detroit area expands, so, too, does its residents' girth. Detroit News. 2001; E01

16. Montgomery L. Suburbia's road to weight gain: land-use designs discourage pounding the pavement, some say. Washington Post. 2002; C01.

17. National Conference of State Legislatures, Physical Activity and Walkable Communities. Available at: www.ncsl.org/programs/health/physical.htm. Accessed April 15, 2003.

18. Wilkinson WC, Eddy N, MacFadden G, Burgess B. Increasing Physical Activity Through Community Design: A Guide for Public Health Practitioners. Washington, DC: National Center for Bicycling and Walking; 2002.

19. Benfield FK, Raimi M, Chen D. Once There Were Greenfields: How Urban Sprawl is Undermining America's Environment, Economy, and Social Fabric. Washington, DC: Natural Resources Defense Council; 1999:215.

20. Ewing R. Los Angeles-style sprawl desirable? J Am Planning Assoc. Winter 1997:94-126.

21. Congress for the New Urbanism, Charter of the New Urbanism. Available at: www.cnu.org. Accessed April 9, 2003.

22. Smart Growth Network, Smart Growth America. Available at: www.smartgrowth.org. Accessed April 15, 2003.

23. Crane R. The influence of urban form on travel: an interpretative review. J Planning Lit. 2000;15(1):3-23.

24. Ewing R, Cervero R. Travel and the built environment: a synthesis. Transportation Res Record. 2001;1780:87-112.

25. Handy SL. Methodologies for exploring the link between urban form and travel behavior. Transportation Res D. 1996;1 (2):151-165.

26. Active Living by Design. Active Living Policies and Environmental Studies Program. Available at: www.alpes.ws. Accessed February 15, 2003.

27. Hoefer WR, McKenzie TL, Sallis JF, Marshall SJ, Conway TL. Parental provision of transportation for adolescent physical activity. Am J Prev Med. 2001;21:48-51.

28. Hofferth SL, Sandberg JF. Changes in American Children's Time 1981-1997. Ann Arbor, Mich: Populations Studies Center, Institute for Social Research, University of Michigan; 2000.

29. Fields J, Smith K, Bass LE, Lugaila T. A Child's Day: Home, School, and Play (Selected Indicators of Child Well-Being). Washington, DC: Census Bureau; 2001
30. Welk GC, Corbin B, et al. Measurement issues in the assessment of physical activity in children. Res $Q$ Exerc Sport. 2000;71(2):59-73.

31. Clifton KJ. Independent mobility among teenagers: an exploration of travel to after school activities. Paper presented at: Transportation Research Board; 2003; Washington, DC.

32. Brustad RJ. Attraction to physical activity in urban schoolchildren: parental socialization and gender influences. Res Q Exerc Sport. 1996;67:316-323.

33. Sallis JF, Owen N. Physical Activity E Behavioral Medicine. Sage Publications; 1999.

34. Kahn EB, Ramsey LT, Brownson RC, et al. The effectiveness of interventions to increase physical activity: a systematic review. Am J Prev Med. 2002; 22:73-107.

35. Pate R, Sirard J. Physical activity and young people. Topics Nutr. 2000:118

36. Sallis JF, Prochaska JJ, Taylor WC. A review of correlates of physical activity of children and adolescents. Med Sci Sport Exerc. 2000;32:963-975.

37. Varian H. Microeconomic Analysis. Norton; 1992.

38. Zakarian JM, Hovell MF, Hofstetter CR, Sallis JF, Keating KJ. Correlates of vigorous exercise in a predominantly low SES and minority high school population. Prev Med. 1994;23:314-321.

39. Craig S, Goldberg J, Dietz WH. Psychosocial correlates of physical activity among fifth and eighth graders. Prev Med. 1996;25:506-513.

40. Stucky-Ropp RC, DiLorenzo TM. Determinants of exercise in children. Prev Med. 1993;22:880-889.

41. Sallis JF, Alcaraz JE, McKenzie TL, Hovell MF. Predictors of change in children's physical activity over 20 months. Am J Prev Med. 1999;16:222229.

42. Sallis JF, Prochaska JJ, Taylor WC, et al. Correlates of physical activity in a national sample of girls and boys in grades 4 through 12. Health Psychol. 1999;18:410-415.

43. McKenzie TL, Marshall SJ, Sallis JF, Conway TL. Leisure-time physical activity in school environments: an observational study using SOPLAY. Prev Med. 2000;30:70-77.

44. Pikora T, Giles-Corti B, Bull F, Jamrozik K, Donovan R. Developing a framework for assessment of the environmental determinants of walking and cycling. Soc Sci Med. 2003;56:1693-1703.

45. Kelder SH, Perry CL, Kleep KI, Lytle LL. Longitudinal tracking of adolescent smoking, physical activity, and food choice behaviors. Am J Public Health. 1994;84:1121-1126.

46. McLeroy KR, Bibeau D, Steckler A, Glanz K. An ecological perspective on health promotion programs. Health Educ O. 1988;15:351-377.

47. Sallis JF, Owen N. Ecological models. In: Glanz K, Lewis FM, Rimer BK. Health Behavior and Health Education: Theory Research and Practice. San Francisco, Calif: Jossey-Bass; 1997:403-424.

48. Stokols D. Establishing and maintaining health environments: toward a social ecology of health promotion. Am Psychol. 1992;47:6-22.

49. Van Vliet W. Children's travel behavior. Ekistics. 1983;50(298):61-65.

50. Gurin DB. Travel patterns of suburban high school males and programs to increase their mobility. In: Transportation Research Record. Washington, DC: Transportation Research Board, National Research Council; 1974:112.

51. Tranter P, Pawson E. Children's access to local environments: a case study of Christchurch, New Zealand. Local Environ. 2001;6(1):27-48.

52. Zahavi Y. Travel Time Budget and Mobility in Urban Areas. Washington, DC: US Dept of Transportation; 1974.

53. Levinson D, Kumar A. Activity, travel, and the allocation of time. J Am Planning Assoc. 1995;61:458-470.

54. Mokhtarian P, Chen C. To TTB or not to TTB: that is the question. Paper presented at: Transportation Research Board; 2003; Washington, DC.

55. Reichman S. Travel adjustments and life styles: a behavioral approach. In: Stopher PR, Meyburg AH, eds. Behavioral Travel-Demand Models. Lexington, Mass: Lexington Books; 1976:143-152.

56. Blair SN, Kohl HW III, Gordon NF. Physical activity and health: a lifestyle approach. Med Exerc Nutr Health. 1992;1:54-57.

57. Centers for Disease Control and Prevention. Increasing physical activity: a report on recommendations of the Task Force on Community Preventive Services. MMWR. 2001;50(RR-18):1-14. 